judgment-while no expert in his or her senses will want to agree to give time to further advisory work on behalf of the DHSS while such attitudes persist.

Sir Douglas Black's working group on inequalities in health was set up in 1977 by the Labour Government. Its four members assembled a vast mass of data. Their main finding was that in the 1960s and 1970s the health of the poorer sections of our society did not improve and in some respects deteriorated. Their recommendations were intended to give children a better start in life and to encourage good health among a larger proportion of the population. Much of the emphasis was on preventive approaches, education, and sustained drive against child poverty.

$\mathrm{Mr}$ Jenkin clearly did not like the report. His dismissive foreword claimed that the recommendations would cost upwards of $£ 2000$ million a year and that they were quite unrealistic "in present or any foreseeable economic circumstances." The Secretary of State added that he was making the report available for discussion-but since only 260 copies were printed ${ }^{3}$ that discussion has not been very wide-ranging. The report was, in plain terms, ditched.

The House of Commons' Social Services Committee examined perinatal and neonatal mortality between 1979 and 1980 , reporting last summer. ${ }^{2}$ The report was again backed by solid data, reviewed and discussed with the help of the three medical advisers. The MPs visited NHS maternity units all over the country and took evidence from hundreds of sources. Again, the main findings were the inequalities in the health of different sections in our society, and the recommendations were intended to narrow those differences.

This time Mr Jenkin has not ignored the report; instead, he has strangled it. In his reply ${ }^{4}$ he claims that he wants to "discourage unrealistic expectations which the Committee's report may have aroused of the number of deaths and serious handicaps which are avoidable and the ease with which they could be prevented." He has rejected most of the fundamental recommendations-the setting of standards and norms for staffing and equipment; the further discouragement of home delivery; an increase in the provision of neonatal intensive care unit cots and the designation of subregional perinatal centres; and a ban of tobacco advertisements and a warning of its adverse effects on cigarette packets. Other fundamental proposals-on confidential inquiries into perinatal deaths, for a differential pay incentive for midwives, and an increase in the numbers of consultant paediatricians-have been ducked by reference to health authorities and professional bodies.

Most important, $\mathrm{Mr}$ Jenkin has refused to give maternity and neonatal services the overriding priority recommended by the committee; health authorities are to be left free to make their own choices on priorities. He flatly rejects the committee's argument that the cost of its recommendations would be far outweighed by the savings they would produce. In plain terms, he refused to believe the report.

No one disputes the severity of the Government's economic problems; we would not have criticised Mr Jenkin for saying that since there is no money the proposals will have to be deferred. In both cases the experts responsible for the reports had hoped that their work might lead to a policy being adopted-a long-term strategy for the narrowing of the differences between the top and bottom layers of our society. Instead they have been told that they wasted their time. Mr Jenkin's anonymous advisers know better: the experts are wrong.

Just one year ago we complained about the flight from science ${ }^{5}$ the growing trend for politicians and the public to reject expert advice on emotional or doctrinaire grounds. 1980 has seen the trend continue: the two outstanding examples have been Debendox and brain death, where the evidence of the experts has been submerged by shock-horror journalistic techniques.

The danger for our society is that the experts are losing patience. Membership of a working party or an advisory committee (on drugs, brain death, manpower, medical education) is demanding in terms of both time and mental energy. The few really top-class advisers have many other demands on their services. They will not serve on committees whose work is discarded with the shallow indifference that is becoming common.

1 Working Group on Inequalities in Health. Report. London: HMSO, 1980. (Black Report.)

${ }^{2}$ House of Commons Social Services Committee. Session 1979-80, second report: perinatal and neonatal mortality. London: HMSO, 1980. (Short report.)

${ }^{3}$ Morris JN. Inequalities in health. $\mathrm{Br} \mathrm{Med} \mathcal{F} 1980 ; 281: 1003$.

4 Department of Health and Social Security. Reply to the second report from the Social Services Committee on Perinatal and Neonatal Mortality. London: HMSO, 1980.

${ }^{5}$ Anonymous. The flight from science. $\mathrm{Br} M e d \mathcal{F} 1980 ; 280: 1-2$.

\section{Out of step}

The 1980s have started badly, not least in preventive medicine. Future generations will find it difficult to understand how successive British governments managed to remain out of step with the civilised world. There was no lack of objective evidence, but, with 100000 premature deaths every year from cigarette smoking, they countenanced the ineffectual fatuity of the new agreement with the tobacco industry, and, with some 42000 casualties associated with drink and driving, they failed to enforce the law; with the knowledge that seat belts would save a minimum of 600 deaths and 11000 serious injuries a year, they refused to introduce a Bill to make wearing them compulsory. There was no lack of evidence from other countries that such measures could be implemented: Finland, Norway, and Eire had shown that legislation could control tobacco promotion; countries as diverse as Sweden and Yugoslavia had found ways to enforce strict drink/driving laws; and virtually the whole of the rest of the civilised world passed laws to make seat-belt wearing compulsory.

If Britain is belatedly to legislate on preventive medicine, then, the impetus is likely to come from outside pressure groups rather than our elected representatives, supposedly responsible for the public health. The BMA and the royal colleges have continued their tradition of writing to ministers as well as making important public statements on health policy; Action on Smoking and Health and the Medical Council on Alcoholism are examples of established bodies concerned with a specific topic; and, encouragingly, there are signs that ad-hoc groups are being formed by local initiativeas, for example, the Wessex Positive Health Team's recent campaign for seat-belt legislation.

Individually, however, few of these bodies seem likely to be able to sustain the necessary campaigns for Britain's need for effective preventive medicine and to overcome official laissez-faire. A year ago, in discussing whether Britain needed an academy of medicine, we said that the time had come for various sections of the profession to consider combining to meet the wider medical needs. Today that need is more urgent. 